\title{
A Qualitative Study on Perspectives and Lived Experiences of Caregivers of Individuals With Hoarding Behaviour in an Asian Population
}

\section{Dear Editor,}

Anationwide mental health survey of Singapore's general population has established the prevalence of hoarding at $2 \% .{ }^{1}$ Despite its relatively low prevalence, hoarding often captures the attention of the media. The media's focus has largely been on the individual with hoarding behaviour and less is covered on the distress of family members who are living with or who are involved in the care of these individuals. Given that the dominant household structure in Singapore is that of the nuclear family, such a living arrangement suggests the considerable impact hoarding has on caregivers. Studies have found that having a childhood experience of living with a family member who hoards was associated with childhood distress and family strain. ${ }^{2,3}$ In qualitative studies conducted in the United Kingdom and the United States involving family caregivers, their narratives highlighted the hardships they faced and included themes on "loss of normal family life", "the need for understanding", "impact on relationships", "marginalisation", "internal barriers to seeking support" and "internal conflicts". ${ }^{4-5}$ There is, however, a dearth of studies examining the lived experiences of caregivers in the local context. A qualitative study was thus conducted with the aim of understanding the lived experiences of caregivers of individuals with hoarding behaviour and their perspectives of hoarding behaviour in terms of the challenges that they have encountered. To the best of our knowledge, this is one of the first studies examining the lived experiences of caregivers in the local context. Findings from the study will help bridge the gap in the extant literature and provide valuable insights for service providers in supporting caregivers and family members of individuals with hoarding behaviour.

\section{Materials and Methods}

A purposive sample of caregivers was obtained through referrals from psychiatrists at a tertiary psychiatric hospital and from community agencies involved in the management of hoarding behaviour. Caregivers were family members of individuals who were either diagnosed with hoarding disorder (with or without comorbidity) by a psychiatrist or identified by community agencies to have significant social and functional impairment due to hoarding. The caregivers were also living with or had lived with these individuals and provided care for them. Face-to face, semi-structured interviews were conducted with caregivers individually using an interview guide. Questions asked included the following topics: relationship of caregiver with the individual with hoarding behaviour, onset and progress of hoarding behaviour, objects acquired, any perceived reasons behind the hoarding behaviour, their experiences of living with the individual with hoarding behaviour, experiences with clearing the clutter and treatment-seeking. Interviews were audio-recorded and transcribed verbatim.

\section{Data Analysis}

An inductive qualitative approach was used to analyse the data, thereby allowing for the emergence of themes with the goal of answering the research questions. ${ }^{6}$ Three of the authors (JV, SC and ES) independently conducted an initial analysis of the first 3 transcribed interviews to obtain preliminary themes. Data from each transcript was broken down into smaller units and were assigned relevant codes according to their content. These codes were then grouped together according to their concepts to create an initial list of preliminary themes which subsequently formed emergent themes following discussions within the team. The remaining transcripts were subsequently coded and higher order themes were then derived from the combination of emergent themes based on their interrelation and cooccurrence in the interviews. Consensus was reached upon discussions and iterative examination of codes and themes. Where disagreements occurred and could not be reconciled within the team, views were sought from the senior coauthor (MS) who is an experienced qualitative researcher.

\section{Results}

A total of 10 caregivers had participated in the study. The sociodemographic profile of the participants is shown in Table 1. Age of the participants ranged from 23-66 years old and majority were of Chinese ethnicity. Four superordinate themes emerged from the data collected: 1) caregivers' understanding of hoarding behaviour, 2) conflicts with those with hoarding behaviour, 3 ) impact on caregivers' personal life, and 4) help received by caregivers. These themes are described in this section with the related verbatim quotes derived from the transcripts shown in Table 2. 
Table 1. Sociodemographic Profile of Caregivers

\begin{tabular}{|c|c|c|c|c|}
\hline $\begin{array}{l}\text { Caregiver } \\
\text { Number }\end{array}$ & Gender & Marital Status & Employment & $\begin{array}{l}\text { Relationship With individual } \\
\text { With Hoarding Behaviour }\end{array}$ \\
\hline 1 & Male & Single & Full-time & Child \\
\hline 2 & Female & Single & Unemployed & Sibling \\
\hline 3 & Female & Married & Unemployed & Sibling \\
\hline 4 & Female & Single & Full-time & Niece \\
\hline 5 & Female & Single & Full-time & Child \\
\hline 6 & Female & Married & Part-time & Spouse \\
\hline 7 & Male & Married & Part-time & Sibling \\
\hline 8 & Male & Single & Full-time & Child \\
\hline 9 & Female & Married & Full-time & Spouse \\
\hline 10 & Male & Widowed & Unemployed & Parent \\
\hline
\end{tabular}

Table 2. Verbatim Quotes From Caregivers

\begin{tabular}{|c|c|c|c|}
\hline Theme and Subtheme & Caregiver Number & Gender & Quote \\
\hline \multirow[t]{3}{*}{$\begin{array}{l}\text { Caregivers' understanding of } \\
\text { hoarding behaviour }\end{array}$} & 5 & Female & $\begin{array}{l}\text { There's a little bit of hatred like why is she keeping so much things? I just don't } \\
\text { understand her and she just doesn't make sense to me. }\end{array}$ \\
\hline & 3 & Female & $\begin{array}{l}\text { He lost his wife, even though he's not the one who want to divorce his wife... } \\
\text { personally (I) think because of the loss, so he may want to have a sense of } \\
\text { possession or something that belongs to him, so you just don't take anything } \\
\text { away from him. }\end{array}$ \\
\hline & 9 & Female & $\begin{array}{l}\text { This kind of person, I also don't know what to say because maybe his brain is } \\
\text { not good or he is greedy or what. I think he is greedy. }\end{array}$ \\
\hline
\end{tabular}

\begin{tabular}{|c|c|c|c|}
\hline \multicolumn{4}{|c|}{$\begin{array}{l}\text { Conflicts with individuals with } \\
\text { hoarding behaviour }\end{array}$} \\
\hline \multicolumn{4}{|l|}{ Ceasing acquisition } \\
\hline & 9 & Female & $\begin{array}{l}\text { Talking about all this. It's hard to tell him because every time we ask him not to } \\
\text { bring things back, he will say... he is very stubborn, say this, say that. }\end{array}$ \\
\hline & 8 & Male & $\begin{array}{l}\text { I just angry... say, "You keep these things for what, keep keep keep, some } \\
\text { things huh.” I told her if you buy the things you keep, I don't mind. That's } \\
\text { why you don't saw me asking you throw your clothes. But those things outside } \\
\text { people throw away, you go and pick, no use, I don't even use, I don't even } \\
\text { touch. If you want, you can just sell it to karang guni." I have no... I'm ok with } \\
\text { that. Don't one two days, don't keep there say you want to sell and then you put } \\
\text { there and after one year later, it's still down there. You don't want to sell, just } \\
\text { throw it. Then the thing escalated, then we just quarrel. }\end{array}$ \\
\hline \multirow[t]{3}{*}{ Clearing of clutter } & 5 & Female & $\begin{array}{l}\text { When she found out after that, she will just, she will cry, she will like, "Why } \\
\text { you throw away my things without my consent? You are disrespectful. How } \\
\text { can you do this to your mother?" Then she will go on for weeks, then she will } \\
\text { complain to my aunt. }\end{array}$ \\
\hline & 8 & Male & $\begin{array}{l}\text { She say this is not your problem, she say, this house is belong to dad and her. } \\
\text { Not mine. If I'm not happy, ask me to move out because she say, do what she } \\
\text { want to do, it's her own problem. She asks us not to intervene. Not to interfere } \\
\text { what she wants to do. }\end{array}$ \\
\hline & 10 & Male & $\begin{array}{l}\text { Once you throw away her things or touch her things, she will shout and scream. } \\
\text { It agitated her. }\end{array}$ \\
\hline
\end{tabular}

"Rag and bone man - someone who makes a living by rummaging for refuse in the streets or collecting items or materials from someone for salvage. 
Table 2. Verbatim Quotes From Caregivers (Cont'd)

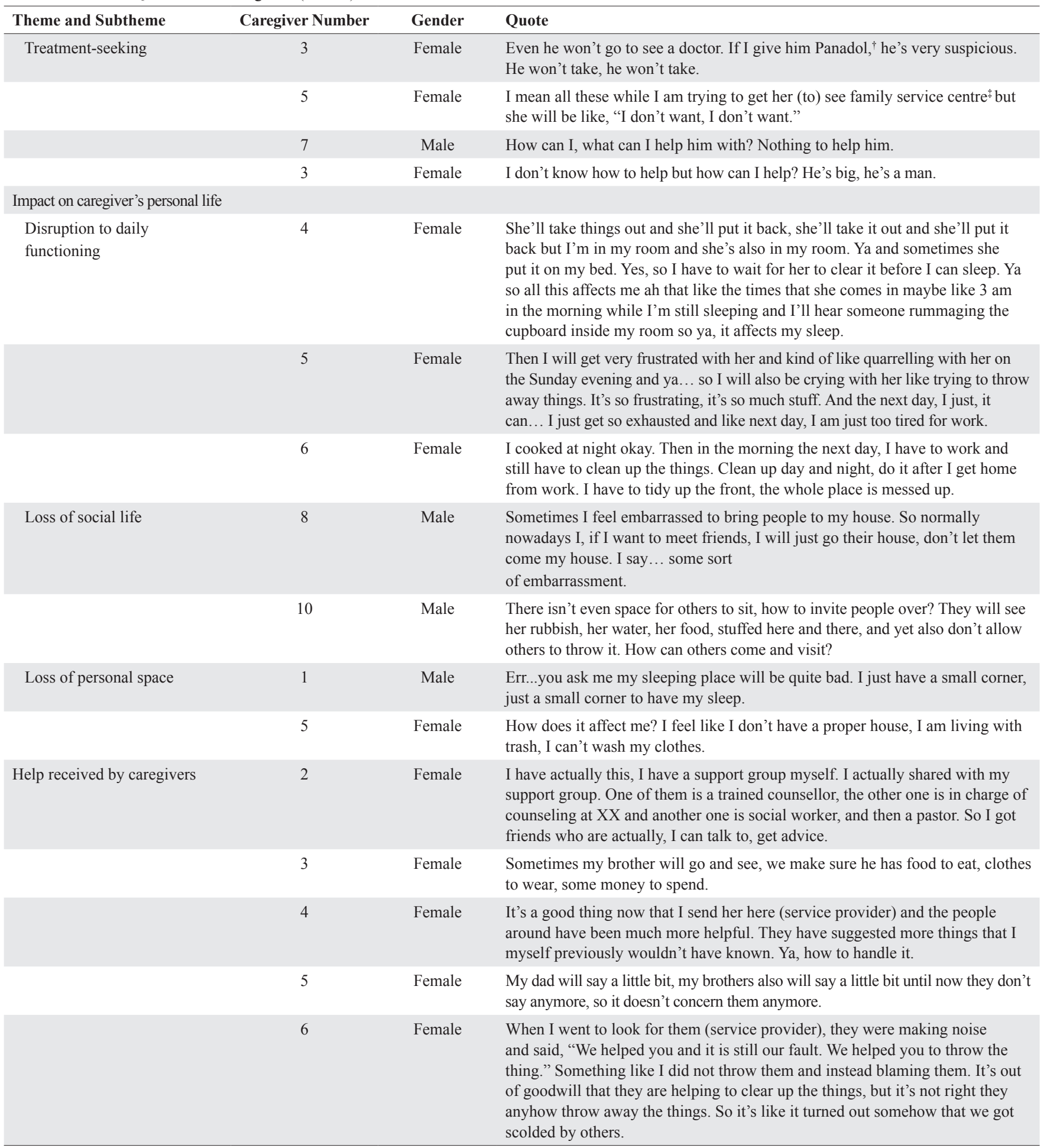

${ }^{\dagger}$ Acetaminophen.

Community-based agency which provides help and support to individuals and families in need. 


\section{Caregivers' Understanding of Hoarding Behaviour}

Participants described their relatives' hoarding behaviour including the items they acquired, sources of their acquisition, frequency and routine of their acquiring behaviour. Their narratives reflected an observable strain in trying to understand these behaviours, specifically on their relatives' need to obtain certain types of items in quantities which they deemed excessive. It was also common amongst participants to believe in the possibility of an underlying mental illness to account for their relatives' irrational behaviour.

\section{Conflicts With Individuals With Hoarding Behaviour}

Participants reported facing conflicts with their relatives when managing their hoarding behaviours. For the majority, disagreements often centred on dealing with ceasing acquisition, clearing of clutter and treatment-seeking. Importantly, poor insight into their hoarding behaviours often formed the basis of conflicts as they disagreed on acceptable behaviours in the house. Many had tried to reason with their relatives by addressing specific concerns such as its lack of utility and value, safety and hygiene. However, their opinions and advices were often met with negative reactions. Aside from the loss of shared living spaces, the clutter resulted in difficulties navigating around the house and carrying out of household chores, therefore spurring them to clear the clutter (which was usually done without the permission of their relatives). When discovered by their relatives, arguments tended to ensue and feelings of betrayal were often expressed. Unfortunately, getting their relatives to seek professional treatment was also often met with resistance and left caregivers feeling helpless and uncertain on how they could help their relatives.

\section{Impact on Caregivers' Personal Life}

There were many effects on participants' lives due to their relatives' hoarding behaviour. These include disruption in daily functioning, loss of social life and personal space. Participants mentioned that they were embarrassed to invite guests to their house due to the clutter and its unkempt condition. Furthermore, when clutter extended into the personal space of their bedroom, their work and sleep were severely compromised. The hygiene of their personal space also worsened due to the nature of the items that were acquired and the fact that cleaning was made more difficult due to the clutter.

\section{Help Received by Caregivers}

For participants, supporting their relatives and managing their hoarding behaviours were overwhelming at times. Many had to seek help for themselves to ameliorate the burden that they were experiencing. Sources and types of help that they had received came largely from informal sources such as other family members and friends, as well as from formal social services. Participants had also sought support for the management of their relatives' hoarding behaviour and welfare (e.g. daily needs such as providing clothing and food), emotional support and financial aid. Support received from service providers also provided greater understanding on how to deal with hoarding behaviour.

However, there were others who felt that they had received insufficient support, no support or that the support they received was unhelpful. There were participants who mentioned that their family members were not rendering sufficient help or had given up on their relatives altogether.

\section{Discussion}

Hoarding is a community problem as it compromises the well-being of the individuals who hoard and also of those who live with them. ${ }^{7}$ In fact, the latter face the same health and safety risks such as respiratory problems, risk of being in a fire or sustaining fall injuries due to the clutter. ${ }^{8}$ In the present study, caregivers' narratives offered detailed descriptions of the impact of hoarding on themselves and covered themes like disruption in daily functioning and loss of social lives. This finding is consistent with the literature on Western countries where family burden and distress amongst relatives of individuals with hoarding behaviour are often reported..$^{2-5,9}$

The need to understand hoarding behaviour is a common theme that has emerged from other qualitative interviews with caregivers and family members of individuals with hoarding behaviour. ${ }^{4,5}$ Sampson $^{5}$ posited that with an understanding of the behaviour, caregivers will be able to see the problems they faced more clearly and with a better direction to cope and manage the hoarding behaviour. ${ }^{5}$

In terms of the adequacy and effectiveness of help that caregivers themselves had received, a mixture of responses was given. Importantly, none of the caregivers reported attending psychoeducational programmes or therapy-based services for the stress and burden they experienced. The findings also suggest an inadequacy of support servicesparticularly formal services - for caregivers. This could also have been due to a lack of awareness of such services.

There are some limitations in this study. In terms of ethnic background of caregivers, there was an overrepresentation of Chinese ethnicity and thus culturally-specific themes that may have emerged from the analysis were not observed. This study had a small sample size and was unable to distinguish stress faced by caregivers (in other studies, it was found that female caregivers of individuals with Alzheimer's disease and stroke had poorer mental health). ${ }^{10-11}$ Additionally, all the caregivers were residing 
in public housing. Getting the perspectives of caregivers residing in private housing would allow the development of a more comprehensive understanding of the condition and experiences in the community.

\section{Conclusion}

Findings from the qualitative analysis of the present data were in many ways congruent with other studies in the literature that cited the burden and strains that caregivers of individuals with hoarding behaviour experienced. Results from this study can inform service providers who manage hoarding behaviours in the community on the types of programmes that are potentially useful to caregivers, for example, family-based interventions that can help to improve understanding of hoarding and overall well-being. This is the first study to explore the impact of hoarding behaviours on caregivers Singapore through qualitative interviews. It paves the way for future studies to further examine hoarding in Singapore and the care that will be needed for individuals affected by hoarding.

\section{Acknowledgement}

The study was funded by the Agency for Integrated Care, Housing and Development Board and Ministry of National Development. The authors would like to thank the caregivers for taking time to participate in the research study and for generously sharing their experiences.

\section{REFERENCES}

1. Subramaniam M, Abdin E, Vaingankar JA, Picco L, Chong SA. Hoarding in an Asian population: prevalence, correlates, disability and quality of life. Ann Acad Med Singapore 2014;43:535-43.

2. Tolin DF, Frost RO, Steketee G, Fitch KE. Family burden of compulsive hoarding: results of an internet survey. Behav Res Ther 2008;46:334-44.

3. Rees CS, Valentine S, Anderson RA. The impact of parental hoarding on the lives of children: interviews with adult offspring of parents with hoarding disorder. Clinical Psychologist 2018;22:327-35.
4. Wilbram M, Kellett S, Beail N. Compulsive hoarding: a qualitative investigation of partner and carer perspectives. Br J Clin Psychol 2008;47:59-73.

5. Sampson JM. The lived experience of family members of persons who compulsively hoard: a qualitative study. J Marital Fam Ther 2013;39:388-402.

6. Braun V, Clarke V. Using thematic analysis in psychology. Qualitative Research in Psychology 2006;3:77-101.

7. Frost RO, Steketee G, Williams L. Hoarding: a community health problem. Health Soc Care Community 2000;8:229-34.

8. Kim HJ, Steketee G, Frost RO. Hoarding by elderly people. Health Soc Work 2001;26:176-84.

9. Drury H, Ajmi S, Fernández de la Cruz L, Nordsletten AE, Mataix-Cols D. Caregiver burden, family accommodation, health, and well-being in relatives of individuals with hoarding disorder. J Affect Disord 2014;159:7-14.

10. Sallim AB, Sayampanathan AA, Cuttilan A, Ho R. Prevalence of mental health disorders among caregivers of patients with Alzheimer disease. $\mathrm{J}$ Am Med Dir Assoc 2015;16:1034-41.

11. Loh AZ, Tan JS, Zhang MW, Ho RC. The global prevalence of anxiety and depressive symptoms among caregivers of stroke survivors. J Am Med Dir Assoc 2017;18:111-6.

Ellaisha Samari, ${ }^{* 1}{ }_{B A}$, Sherilyn Chang, ${ }^{{ }_{1}}{ }_{B S O C S C}$, Janhavi Vaingankar, ${ }^{1}$ MSc, Siow Ann Chong, ${ }^{1}$ MBBS, MMed, Anitha Jeyagurunathan, ${ }^{1}$ MPhil, Fiona Devi Siva Kumar, ${ }^{1}{ }_{B A}$, Richard R Goveas, ${ }^{2}$ MBBS, MRC Psych, Kelvin $\mathrm{Ng},{ }^{3}$ MBBS, MMed, Weng Mooi Tan, ${ }^{4}$ PharmD, EMBA, Rebecca Chong, ${ }^{4}$ MA, Peishan $\underline{\text { Ye }},{ }_{B A}^{4}$, Lea Lea Lim, ${ }^{5} B S c$, Ramzi Babjee, ${ }^{6}{ }_{M S c}$, Mythily $\underline{\text { Subramaniam, }}{ }^{1}$ MBBS, MHSM

${ }^{*}$ Co-first authors

${ }^{1}$ Research Division, Institute of Mental Health, Singapore

${ }^{2}$ Department of Geriatric Psychiatry, Institute of Mental Health, Singapore

${ }^{3}$ Department of Community Psychiatry, Institute of Mental Health, Singapore ${ }^{4}$ Community Mental Health Division, Agency for Integrated Care, Singapore

${ }^{5}$ Housing Management Group, Housing and Development Board, Singapore

${ }^{6}$ Municipal Services Office, Ministry of National Development, Singapore

Address for Correspondence: Ms Sherilyn Chang, Research Division, Institute of Mental Health, 10 Buangkok View, Singapore 539747.

Email: sherilyn sh chang@imh.com.sg 